\title{
In vitro macrophage nitric oxide production by Pterospartum tridentatum (L.) Willk. inflorescence polysaccharides
}

\author{
Vitor M.R. Martins ${ }^{\mathrm{a}, \mathrm{b}}$, Joana Simões ${ }^{\mathrm{a}}$, Isabel Ferreira ${ }^{\mathrm{c}, \mathrm{d}}$, Maria Teresa Cruz ${ }^{\mathrm{c}, \mathrm{d}}$, \\ M. Rosário Domingues ${ }^{a}$, Manuel A. Coimbra ${ }^{a}, *$ \\ a QOPNA and Departamento de Química, Universidade de Aveiro, Campus de Santiago, 3810-193 Aveiro, Portugal \\ b CIMO-ESA, Instituto Politécnico de Bragança, Campus de Santa Apolónia, 5301-855 Bragança, Portugal

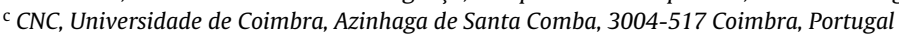 \\ d Faculdade de Farmácia, Universidade de Coimbra, 3000-548 Coimbra, Portugal
}

\section{A R T I C L E I N F O}

\section{Article history:}

Received 10 August 2016

Received in revised form

14 September 2016

Accepted 26 September 2016

Available online 28 September 2016

\section{Keywords:}

P. tridentatum

Acetylated galactomannan

Pectic polysaccharides

Mass spectrometry

Nitric oxide

\begin{abstract}
A B S T R A C T
Pterospartum tridentatum (L.) Willk. decoctions of dried inflorescences are used in Portugal due to their claimed beneficial properties for various health disorders. To disclose the potential contribution of its polysaccharides to health benefits, in this work, hot water extracts from $P$. tridentatum inflorescences were prepared and fractionated by ethanol precipitation and anion exchange chromatography. The fraction rich in acetylated galactomannans evidenced an increase in nitric oxide (NO) production by macrophages. This activity decreased $60-75 \%$ after saponification, confirming that acetylation is an important structural feature for this biological property. In addition, the treatment of pectic polysaccharides with endopolygalacturonase showed that type-I and type-II arabinogalactans, as well as low molecular weight galacturonans and xyloglucans, may also contribute to macrophage NO production. Thus, the polysaccharides present in $P$. tridentatum dried inflorescences may contribute to the health beneficial properties frequently attributed to the decoctions of this plant.
\end{abstract}

(C) 2016 Elsevier Ltd. All rights reserved.

\section{Introduction}

Pterospartum tridentatum (L.) Willk. (Fabales order) is a broom like Iberian shrub of the Fabaceae family very common Portuguese north-eastern region of Trás-os-Montes, known as "carqueja" or "carqueija". This small shrub alternates branches and coriaceous winged stems (Franco, 1971; Teixeira \& Pereira, 2004) and its inflorescences are either used in traditional medicine or to flavour rice and roasted meat (Oliveira \& Neiva, 2001; Ribeiro, Monteiro, \& Silva, 2000). The $P$. tridentatum inflorescences are picked during early spring and subsequently dried for the preparation of hot water extracts that, according to the popular tradition, provide protection against various health disorders, such as type 2 diabetes, influenza, and hypertension (Carvalho, 2010, nullChapter ; Neves, Matos, Moutinho, Queiroz, \& Gomes, 2009; Vitor et al., 2004). The composition of the essential oils (Grosso et al., 2007), as well as the role of the flavonoids from $P$. tridentatum water extracts as protectors against endothelial oxidative injury have been investigated (Vitor et al., 2004). However, as far as we know, the polysaccharide

\footnotetext{
* Corresponding author.

E-mail address: mac@ua.pt (M.A. Coimbra).
}

components of the hot water extracts from $P$. tridentatum dried inflorescences remain unknown.

The contribution of botanical polysaccharides to macrophage immunostimulatory activity has been highlighted in various studies (Ferreira, Passos, Madureira, Vilanova, \& Coimbra, 2015; Paulsen, 2001; Ramberg, Nelson, \& Sinnott, 2010; Schepetkin \& Quinn, 2006; Tzianabos, 2000; Yang, Lu, Hsieh, \& Lin, 2014). Indeed, plant aqueous extracts containing pectic polysaccharides are frequently reported to possess macrophage immunostimulatory activity (Cheng et al., 2014; Inngjerdingen, Kiyohara et al., 2007; Inngjerdingen, Patel et al., 2007; Inngjerdingen, Inngjerdingen, Patel, Allen, \& Chen Rolstad, 2008; Le Normand et al., 2014; Paulsen \& Barsett, 2005; Zou et al., 2014). Pectic polysaccharides are a major plant cell wall component, defined as a hetero-polysaccharide predominantly containing galacturonic acid residues (Voragen, Coenen, Verhoef, \& Schols, 2009). Pectic polysaccharides often contain neutral sugars as side chains, such as type-I and type-II arabinogalactans (AG-I and AG-II, respectively) (Mohnen, 2008; OíNeill, Albersheim, \& Darvill, 1990), which have been reported to contribute for immunostimulatory activity (Ferreira et al., 2015). Besides pectic polysaccharides, non-starch storage polysaccharides such as galactomannans and xyloglucans, which can be found in the seeds cell walls of some plants from the Fabaceae family, have been also reported as immunostimulators (Joseph, 
Aravind, George, Varghese, \& Sreelekha, 2013; Rosário et al., 2008; Rosário, Kangussu-Marcolino, do Amaral, Noleto, \& Petkowicz, 2011; Simões, Nunes, Domingues, \& Coimbra, 2010; Simões, Nunes, Domingues, Coimbra, \& Domingues, 2012).

Therefore, this study identifies the type of polysaccharides present in hot water extracts of $P$. tridentatum dried inflorescences, providing an insight regarding their structural features and also evaluating their immunostimulatory activity, expressed as macrophage NO production. The relation between polysaccharides structure and the observed immunostimulatory activity will also be under discussion.

\section{Experimental}

\subsection{Plant material, preparation of the hot water extracts (HWE) and high molecular weight material (HMWM)}

The inflorescences of $P$. tridentatum were collected in early Spring in the scrubland near Bragança, north-eastern Portugal. Subsequently, the collected inflorescences were dried in a dark place at room temperature, simulating general conditions of traditional folk use. A voucher specimen of the plant material was identified (BRESA 3045) and deposited at the Herbarium of Escola Superior Agrária de Bragança Portugal. The hot water extracts (HWE) were prepared by the decoction with boiling water of the P. tridentatum dried inflorescences $(0.03 \mathrm{~g} / \mathrm{mL})$, during a total of $2 \mathrm{~h}$. Subsequently, the resulting liquid was filtered through a glass fibre filter (Whatman GF/C), concentrated, dialysed (cut-off $12-14 \mathrm{kDa}$ ) and freeze-dried, to obtain the high molecular weight material (HMWM).

\subsection{Ethanol precipitation}

The HMWM was dissolved in distilled water $(10.0 \mathrm{mg} / \mathrm{mL})$, the solution was stirred for $1 \mathrm{~h}$ at room temperature and centrifuged at $24,400 \mathrm{~g}$ for $20 \mathrm{~min}$ at $4{ }^{\circ} \mathrm{C}$. The cold water insoluble residue obtained (WIppt) was suspended in distilled water, frozen, and freeze-dried. Absolute ethanol was added (50\% ethanol, assuming additive volumes) and left for $1 \mathrm{~h}$ at $4{ }^{\circ} \mathrm{C}$. This solution was then centrifuged and the precipitate obtained (Et50) was removed by centrifugation. Absolute ethanol was added to the supernatant $(75 \%$ ethanol, assuming additive volumes), and the resulting solution was left for $1 \mathrm{~h}$ at $4{ }^{\circ} \mathrm{C}$ and centrifuged. The precipitate obtained (Et75) was removed from the supernatant solution (EtSN). In order to completely remove the ethanol, each precipitate was dissolved in distilled water, rotary-evaporated and freeze-dried.

\subsection{DEAE-Sepharose FF anion exchange chromatography}

Anion exchange chromatography on DEAE-Sepharose FF (Pharmacia), was performed on a $100 \times 1.6 \mathrm{~cm}$ column (XK 100/16, Pharmacia), at a flow rate of $0.5 \mathrm{~mL} / \mathrm{min}$. The Et50 and Et75 samples were dissolved in $50 \mathrm{mM}$ potassium phosphate buffer $\mathrm{pH} 6.5$ $(1.0 \mathrm{mg} / \mathrm{mL})$ and sequentially eluted in the same phosphate buffer, and buffer with $0.125,0.250,0.500$, and $1.00 \mathrm{M} \mathrm{NaCl}$. Fractions $(3.0 \mathrm{~mL})$ were collected and assayed for sugars according to a modification of phenol-concentrated sulfuric acid method (Coimbra, Delgadillo, Waldron, \& Selvendran, 1996). The fractions of interest were pooled, dialysed and freeze-dried.

\subsection{Sugar and linkage analysis}

Neutral sugars were determined by gas chromatography after acid hydrolysis release and conversion to the corresponding alditol acetates, as described by Nunes and Coimbra (2001). The hydrolysis of all fractions was performed in duplicate. Results used have less than $5 \%$ variability in the major component sugars. Uronic acids were determined colorimetrically using $m$-phenylphenol (Blumenkrantz \& Asboe-Hansen, 1973). Glycosidic linkage analysis was performed by methylation of the polysaccharides in order to obtain partially methylated alditol acetates that were subsequently analysed by gas chromatography-mass spectrometry (GC-MS), as described by Nunes and Coimbra (2001). Methylated polysaccharides were also carboxyl reduced with $\mathrm{LiAlD}_{4}$, as described by Coimbra et al. (1996), for identification of the uronic acids and determination of their linkages.

\subsection{Determination of the methyl esterification degree}

The samples were dissolved in a glass vial with distilled water $(2.2 \mathrm{~mL})$, and saponified with $2 \mathrm{M} \mathrm{NaOH}(800 \mu \mathrm{L})$, with a reaction time of $1 \mathrm{~h}$ at $25^{\circ} \mathrm{C}$, as described by Waldron and Selvendran (1990). The saponification reaction was finished with $2 \mathrm{M} \mathrm{HCl}(800 \mu \mathrm{L})$. As internal standard, 1-propanol $(200 \mu \mathrm{L}, 2.5 \mathrm{~g} / \mathrm{L})$ was also added to the vial after saponification. The sample suspension was filtered through a $20.0 \mu \mathrm{m}$ nylon membrane filter. The filtrate was directly injected $(500 \mu \mathrm{L})$ in a GC-FID equipment with a $30 \mathrm{~m}$ length DBWax column, with an internal diameter of $0.53 \mathrm{~mm}$ and a film thickness of $1.0 \mu \mathrm{m}$. The oven temperature program was used as described by Nunes, Rocha, Saraiva, \& Coimbra, (2006): a rise in temperature at a rate of $5^{\circ} \mathrm{C} / \mathrm{min}$ from $50^{\circ} \mathrm{C}$ to $65^{\circ} \mathrm{C}$, another rise at $20^{\circ} \mathrm{C} / \mathrm{min}$ until $185^{\circ} \mathrm{C}$, and then at $35^{\circ} \mathrm{C} / \mathrm{min}$ until $220^{\circ} \mathrm{C}$, and held $1 \mathrm{~min}$ at $220^{\circ} \mathrm{C}$. The injector and detector were set at $250^{\circ} \mathrm{C}$. The flow rate of the carrier gas $\left(\mathrm{H}_{2}\right)$ was set at $6 \mathrm{~mL} / \mathrm{min}$. A calibration curve was constructed for methanol final concentrations from 40 to $400 \mathrm{mg} / \mathrm{L}$. Estimated concentrations were made by peak area comparisons with the area of the known concentration of 1propanol. The results obtained have less than $5 \%$ variability and were expressed as mean of samples prepared in duplicate, and each run in duplicate.

\subsection{Endo-polygalacturonase treatment and Bio-Gel P30 chromatography}

The Et75A fraction was dissolved in $0.1 \mathrm{M} \mathrm{NaOH}$ for deesterification $(10.0 \mathrm{mg} / \mathrm{mL})$ and left for $24 \mathrm{~h}$ at ambient temperature. After neutralization with acetic acid, the de-esterified sample was treated with endo- $\alpha$-D- $(1 \rightarrow 4)$-polygalacturonase $(0.3 \mathrm{U})$ for $72 \mathrm{~h}$ at $40^{\circ} \mathrm{C}$ using $50 \mathrm{mM}$ acetate buffer $(5.0 \mathrm{mg} / \mathrm{mL}), \mathrm{pH} 5.5$, with continuous stirring. The reaction was terminated by heating at $100^{\circ} \mathrm{C}$. Gel filtration chromatography on Bio-Gel P30 (Pharmacia), was performed on a $100 \times 1.6 \mathrm{~cm}$ column (XK 100/16, Pharmacia), at a flow rate of $0.5 \mathrm{~mL} / \mathrm{min}$. Blue dextran, and glucose solutions were separately eluted in order to determine the columns exclusion and inclusion volumes, respectively. The samples were eluted with $50 \mathrm{mM}$ acetate buffer, pH 5.0. Fractions $(3.0 \mathrm{~mL})$ were collected and assayed for sugars by the phenol-sulphuric acid method (Coimbra et al., 1996). The fractions of interest were pooled, dialysed and freeze-dried.

\subsection{Endo- $\beta$-mannanase treatment and Bio-Gel P2 chromatography}

The Et75A fraction was dissolved in a $100 \mathrm{mM}$ Na-acetate buffer $(3.0 \mathrm{mg} / \mathrm{mL}), \mathrm{pH} 5.5$, containing $0.02 \%$ sodium azide and treated with endo- $\beta$ - $(1 \rightarrow 4)$-D-mannanase $(1.0 \mathrm{U})$, for $48 \mathrm{~h}$ at $37^{\circ} \mathrm{C}$, with continuous stirring. The digested material was freeze-dried, redissolved in distilled water, and loaded on a XK 1.6/100 column containing Bio-Gel P2. The column, previously calibrated with DP4 (stachyose), DP2 (cellobiose) and monosaccharide (glucose), was eluted with distilled water using a flow of $0.2 \mathrm{~mL} / \mathrm{min}$. Fractions $(1.0 \mathrm{~mL})$ were collected and assayed for sugars by the phenolsulphuric acid method (Coimbra et al., 1996). Fractions containing 
oligosaccharides were evaporated to dryness. No lyophilisation was performed since it has been shown that it may promote $O$-acetyl migration on galactomannans (Nunes, Domingues, \& Coimbra, 2005).

\subsection{Mass spectrometry analysis}

The electrospray ionization-mass spectrometry (ESI-MS) and electrospray tandem mass spectrometry (ESI-MS/MS) experiments on endo- $\beta$-mannanase treated Et75A fraction were carried out in the positive mode on a Q-TOF 2 mass spectrometer (Micromass, Manchester, UK). The fractions obtained after elution through the Bio-Gel P2 column were dissolved in water and further diluted in methanol/water/formic acid (50:49.9:0.1, v/v/v) and introduced into the electrospray source at a flow rate of $10 \mu \mathrm{L} / \mathrm{min}$. The cone voltage was set at $30 \mathrm{~V}$ and capillary voltage at $3 \mathrm{kV}$. Source temperature was at $80^{\circ} \mathrm{C}$ and desolvation temperature at $150^{\circ} \mathrm{C}$. ESI-MS spectra were acquired scanning the mass range from $\mathrm{m} / \mathrm{z} 100$ to 1500. MS/MS spectra were acquired by collision-induced dissociation (CID) using argon as the collision gas. The collision energy used was set between 25 and $40 \mathrm{eV}$. All spectra were accumulated for $1 \mathrm{~min}$. The data were processed using a MassLynx software (version 4.0).

\subsection{Macrophage cell viability and nitric oxide (NO) production}

In a first approach and in order to select concentrations without cytotoxicity, the effect of Et75A fraction on the macrophage cellular viability was performed using 3-(4,5-dimethylthiazol-2-yl)-2,5diphenyl tetrazolium bromide (MTT) reduction colorimetric assay, as described by Mosmann (1983). The possible endotoxin contamination of Et75A fraction was assessed by its pre-incubation with polymyxin B (1000 U/mL) for $1 \mathrm{~h}$, as described by Yang, Zhao, Wang, \& Mei (2007), and subsequent evaluation of macrophage immunostimulatory activity, expressed as NO production. The macrophage immunostimulatory activity of fraction Et75A, and endo-polygalacturonase treated Et75A-I and Et75A-II fractions, expressed as NO production, was evaluated through the assessment of the nitrite accumulation in the Raw 264.7 macrophage cell line culture supernatants using a colorimetric reaction with the Griess reagent (Green et al., 1982). The Toll-like 4 receptor agonist and strong immunostimulatory compound, lipopolysaccharide (LPS), was used as positive control $(1 \mu \mathrm{g} / \mathrm{mL})$. Raw 264.7 macrophages (ATCC TIB-71) were cultured in an endotoxin-free Dulbecco's Modified Eagle Medium supplemented with $10 \%$ inactivated foetal bovine serum, $100 \mathrm{U} / \mathrm{mL}$ penicillin, and $100 \mu \mathrm{g} / \mathrm{mL}$ streptomycin, at $37{ }^{\circ} \mathrm{C}$ in a humidified atmosphere of $95 \%$ air and $5 \% \mathrm{CO}_{2}$. Briefly, $170 \mu \mathrm{L}$ of culture supernatants were diluted with equal volumes of the Griess reagent, which is composed by [0.1\% (w/v) N-(1-naphthyl)-ethylenediamine dihydrochloride and $1 \%(\mathrm{w} / \mathrm{v})$ sulphanilamide containing $5 \%(\mathrm{w} / \mathrm{v}) \mathrm{H}_{3} \mathrm{PO}_{4}$, and maintained during $30 \mathrm{~min}$ in the dark. The absorbance at $550 \mathrm{~nm}$ was measured using an SLT ELISA automatic microplate reader. Culture medium was used as blank and nitrite concentration was determined from a regression analysis using serial dilutions of sodium nitrite as standard. All the experiments were performed in triplicate, and the results expressed as mean \pm SEM of three independent experiments. Statistical analyses were performed using one-way ANOVA with a Dunnett's multiple comparison test. The statistical tests were applied using GraphPad Prism, version 6.00 (GraphPad Software, San Diego, CA, USA).

\section{Results and discussion}

\subsection{Isolation and fractionation of the polysaccharides from the high molecular weight material (HMWM)}

The polysaccharides present in the HMWM obtained from the hot water extracts (HWE) of Pterospartum tridentatum (L.) Willk. dried inflorescences were fractionated according to their solubility in ethanol aqueous solutions.

The HMWM was composed by $42.0 \%$ of carbohydrates, mainly constituted by uronic acids (UA) and glucose (Glc) residues (46.0 and $32.7 \mathrm{~mol} \%$, respectively), with minor proportions of arabinose (Ara, $4.7 \mathrm{~mol} \%$ ), mannose (Man, $7.2 \mathrm{~mol} \%$ ), and galactose (Gal, $7.5 \mathrm{~mol} \%$ ) residues (Table 1 ).

The dissolution of HMWM in cold water resulted in an undissolved material (WIppt) that accounted for $16.0 \%$ of the HMWM mass, composed only by $26.8 \%$ of carbohydrates, mainly Glc (73.4 mol\%). The ethanol precipitation of the cold water soluble HMWM resulted in 3 fractions: Et50, the material insoluble in 50\% ethanol aqueous solutions, accounting for $31.9 \%$ of the HMWM mass, Et75, the material insoluble in $75 \%$ ethanol aqueous solutions, accounting for $26.5 \%$, and EtSN, the material soluble in $75 \%$ ethanol aqueous solutions, accounting for $25.5 \%$ of the HMWM mass. The Et50 fraction was the richest in carbohydrates (91.5\%), mainly UA residues $(80.5 \mathrm{~mol} \%)$, with small proportions of sugar residues characteristic of pectic polysaccharides (Voragen et al., 2009). The Et75 fraction contained $58.2 \%$ of carbohydrates, mainly composed of UA (30.3 mol\%), Glc (24.2 mol\%), and Man (23.6 mol\%), together with Gal residues ( $13.6 \mathrm{~mol} \%)$. This monomeric composition suggests that besides pectic polysaccharides, other polysaccharides are present. The EtSN fraction contained only $24.8 \%$ of carbohydrates, mainly composed of Glc residues ( $65.6 \mathrm{~mol} \%)$, possibly associated with phenolic compounds, which are very soluble in ethanol solutions (Dai \& Mumper, 2010).

Considering the mass yield and carbohydrate content of each fraction, it was possible to conclude that approximately $53 \%$ of the polysaccharides present in the HMWM precipitated in $50 \%$ ethanol aqueous solutions and $28 \%$ precipitated in $75 \%$. These fractions were further fractionated by anion exchange chromatography on DEAE-Sepharose FF, allowing to obtain 4 fractions for each one, separated according to their charge properties. For both Et50 and Et75 fraction, it was observed that the neutral (A) and the less acidic (B) subfractions were the most abundant and also the richest in carbohydrates (Table 1).

Similar to Et50 fraction, the polysaccharides present in Et50A and Et50B exhibited a monomeric composition that comprised high proportions of UA residues. The saponification of these fractions allowed to observe the release of methanol, which is a characteristic of methylesterified pectic polysaccharides (Mohnen, 2008; OíNeill et al., 1990), allowing to determine a degree of methylesterification of $75.9 \%$ for Et50A and $54.6 \%$ for Et50B.

Fraction Et75A, as observed for Et50A, was also rich in UA residues, $54.1 \%$ of which were methyl esterified. However, contrarily to Et50A, it was also rich in Man, Glc, and Gal residues. The majority of Man residues of Et75 fraction were recovered in Et75A, showing that they are components of a neutral polysaccharide, possibly a galactomannan arising from the inflorescence seeds. The DEAE-Sepharose FF fractionation of both Et50 and Et75 also allowed to obtain more acidic fractions, with sugar compositions characteristic of pectic polysaccharides, similar to those recovered in the neutral fractions (Table 1 ).

In order to elucidate the type of polysaccharides present in the major fractions obtained from the decoctions of $P$. tridentatum dried inflorescences, the glycosidic linkage composition was deter- 
Table 1

Mass yield, total sugars, monosaccharide composition, and methanol content of the fractions isolated from the decoctions of $P$. tridentatum dried inflorescences.

\begin{tabular}{|c|c|c|c|c|c|c|c|c|c|c|c|}
\hline & \multirow[t]{2}{*}{ Yield(mass\%) } & \multirow[t]{2}{*}{ Total Sugar(mass\%) } & \multicolumn{8}{|c|}{ Monosaccharide Composition (mol\%) } & \multirow[t]{2}{*}{ Methanol(mmol/mol UA) } \\
\hline & & & Rha & Fuc & Ara & Xyl & Man & Gal & Glc & UA & \\
\hline HMWM & & 42.0 & 0.9 & 0.0 & 4.7 & 1.3 & 7.2 & 7.5 & 32.5 & 46.0 & nd \\
\hline WIppt & $16.0^{\mathrm{a}}$ & 26.8 & 2.4 & 0.0 & 2.3 & 0.8 & 1.3 & 4.9 & 73.4 & 15.0 & nd \\
\hline Et50 & $31.9^{a}$ & 91.5 & 0.5 & 0.3 & 3.2 & 1.1 & 1.7 & 6.2 & 6.5 & 80.5 & nd \\
\hline Et50A & $51.8^{\mathrm{b}}$ & 87.1 & 0.3 & 0.2 & 3.7 & 2.3 & 5.0 & 8.5 & 6.2 & 73.8 & 759.0 \\
\hline Et50B & $32.4^{\mathrm{b}}$ & 89.7 & 0.7 & 0.0 & 3.5 & 0.4 & 0.1 & 4.4 & 0.8 & 90.1 & 545.8 \\
\hline Et50C & $9.4^{\mathrm{b}}$ & 35.9 & 2.0 & 0.1 & 7.5 & 0.9 & 0.4 & 10.9 & 5.8 & 72.5 & 372.3 \\
\hline Et50D & $6.4^{\mathrm{b}}$ & 16.9 & 2.5 & 0.0 & 9.4 & 1.9 & 1.4 & 19.0 & 23.4 & 42.4 & nd \\
\hline Et75 & $26.5^{\mathrm{a}}$ & 58.2 & 1.0 & 0.5 & 4.4 & 2.4 & 23.6 & 13.6 & 24.2 & 30.3 & nd \\
\hline Et75A & $73.3^{c}$ & 85.3 & 0.0 & 0.0 & 3.0 & 2.6 & 26.1 & 11.8 & 15.1 & 41.3 & 541.1 \\
\hline Et75A-I & $67.2^{\mathrm{d}}$ & 86.7 & 0.2 & 0.2 & 4.3 & 4.3 & 46.9 & 16.4 & 25.6 & 2.2 & nd \\
\hline Et75A-II & $18.1^{\mathrm{d}}$ & 97.4 & 0.0 & 0.0 & 0.1 & 0.2 & 1.1 & 0.9 & 1.2 & 96.5 & nd \\
\hline Et75B & $14.5^{c}$ & 62.1 & 1.9 & 0.2 & 11.1 & 0.6 & 1.4 & 14.6 & 2.3 & 67.7 & 418.1 \\
\hline Et75C & $5.4^{\mathrm{c}}$ & 31.5 & 3.5 & 0.1 & 13.0 & 1.0 & 2.8 & 15.6 & 11.9 & 52.1 & 358.4 \\
\hline Et75D & $6.8^{c}$ & 27.7 & 2.3 & 0.0 & 10.0 & 1.3 & 4.5 & 15.3 & 30.0 & 36.6 & nd \\
\hline EtSN & $25.5^{a}$ & 24.8 & 0.9 & 0.5 & 8.8 & 1.3 & 4.0 & 4.3 & 65.6 & 14.6 & nd \\
\hline
\end{tabular}

nd - not determined.

a expressed relatively to the mass of HMWM.

b expressed relatively to the mass of Et50.

c expressed relatively to the mass of Et75.

d expressed relatively to the mass of Et75A.

mined by methylation and analysed as partially methylated alditol acetates by GC-MS.

\subsection{Glycosidic linkage analysis}

The high proportion of UA residues detected in the Et50 and Et75 fractions, suggesting that pectic polysaccharides were the major type of polysaccharides present in the HWE from P. tridentatum dried inflorescences, was confirmed by the carboxyl reduction with $\mathrm{LiAlD}_{4}$ of methylated polysaccharides. The detection of 2,3,4-trimethyl-1,5,6-triacetyl- $d_{6}$-galactitol allowed to confirm the presence of $(1 \rightarrow 4)$-GalA residues. The enzymatic digestion with endo-polygalacturonase of the Et50A and Et75A fractions followed by size-exclusion chromatography on Bio-Gel P30 (Fig. 1a), and the identification of digested material that comprised approximately $95 \%$ of UA residues (Table 1 ), evidenced the presence of $(\alpha 1 \rightarrow 4)$ GalpA residues.

In order to provide a clearer insight regarding the type of glycosidic linkages of the neutral sugars detected in the decoctions of $P$. tridentatum dried inflorescences, the results of the sugar linkage analysis are presented without the contribution of UA residues (Table 2). For all fractions analysed, the presence of $(1 \rightarrow 3)$ - and $(1 \rightarrow 3,6)$-Galp residues, as well as terminal- and $(1 \rightarrow 6)$-Galp residues, diagnostic of type II-arabinogalactans (AG-II) (Nunes, Reis, Silva, Domingues, \& Coimbra, 2008), evidenced the presence of these polysaccharides in the decoctions of $P$. tridentatum dried inflorescences.

The majority of the fractions analysed presented $(1 \rightarrow 4)$ Galp residues, diagnostic for the presence of AG-I structures (Carpita \& Gibeau, 1993), which are often found attached to the rhamnogalacturonan-I (RG-I) moiety of pectic polysaccharides (Inngjerdingen, Kiyohara et al., 2007; Inngjerdingen, Patel et al., 2007; Inngjerdingen et al., 2008; Peng et al., 2001). The detection of $(1 \rightarrow 2,4)$-Rhap2,4)-Rhap residues in these fractions supports the presence of AG-I in the decoctions from $P$. tridentatum dried inflorescences.

The Et50A and Et75A fractions, not retained in the ion exchange column, exhibited high proportions of $(1 \rightarrow 4)$ - and $(1 \rightarrow 4,6)$-Glcp residues, with ratios of $(1 \rightarrow 4)$ - to $(1 \rightarrow 4,6)$-Glcp of $1: 1$ in fraction Et50A and 1:6 in fraction Et75A. This high relative amount of branched glucose and the presence of T-Fucp, T-Galp, T-Xylp, $(1 \rightarrow 2)$-Galp, and $(1 \rightarrow 2)$-Xylp residues allows to infer the pres- ence of xyloglucans (Fry, 1988; Hayashi \& Kaida, 2011; Hoffman et al., 2005).

High proportions of Man residues, mainly detected in Et75A fraction as $(1 \rightarrow 4)$-Manp and $(1 \rightarrow 4,6)$-Manp residues, together with T-Galp residues, in a proportion similar to that of the $(1 \rightarrow 4,6)$ Man $p$, show the presence of galactomannans in the decoctions of $P$. tridentatum dried inflorescences. These results are in accordance with the water soluble character of galactomannans (Gidley \& Reid, 2006), which are a component of Fabaceae seeds (Srivastava \& Kapoor, 2005), the botanical family of P. tridentatum.

\subsection{Structural characterization of P. tridentatum galactomannans}

In order to reveal the structural features of $P$. tridentatum galactomannans, Et75A fraction, which comprised the highest proportion of galactomannans, was submitted to an endo- $(\beta 1 \rightarrow 4)$ $D$-mannanase treatment. The oligosaccharides obtained from enzymatic hydrolysis were fractionated by size exclusion chromatography (Fig. 1b). The peak eluting near the gel exclusion volume correspond to undigested polysaccharides, namely pectic polysaccharides and xyloglucans, shown to be present in Et75A fraction by linkage analysis (Table 2). It is possible that this material also comprises mannan moieties with structural features that hinder the enzyme action, such as branching points and acetylation (Daas, Schols, \& de Jongh, 2000; Simões et al., 2010, 2012; Simões, Nunes, Domingues, \& Coimbra, 2011).

Fractions corresponding to oligosaccharides resulting from the action of the endo-( $\beta 1 \rightarrow 4)-d$-mannanase were collected and analysed by ESI-MS, showing sodium adduct ions $\left([\mathrm{M}+\mathrm{Na}]^{+}\right)$correspondent to the mannooligosaccharides (Cerqueira et al., 2011; Simões et al., 2010, 2012). Fig. 2a shows, as an example, the ESI-MS spectrum obtained from fraction 21 , evidencing the presence of $[\mathrm{M}+\mathrm{Na}]^{+}$ions of oligosaccharides that correspond to acetylated $\left(\mathrm{Ac}_{1-3} \mathrm{Hex}_{3-4}\right)$ and non-acetylated $\left(\mathrm{Hex}_{2-5}\right)$ series. Since mannose and galactose residues have the same mass, it is not possible to distinguish them by MS, thus, these hexose residues are represented generically by "Hex" although, based on sugar analysis (Table 1), they should be mainly mannose residues.

The structure of all oligosaccharides identified was confirmed by the analysis of their ESI-MS/MS, allowing the identification of the number of hexose units, the presence of acetylated hexoses and the presence of pentose residues. Fig. $2 \mathrm{~b}$ shows, as an 
a)

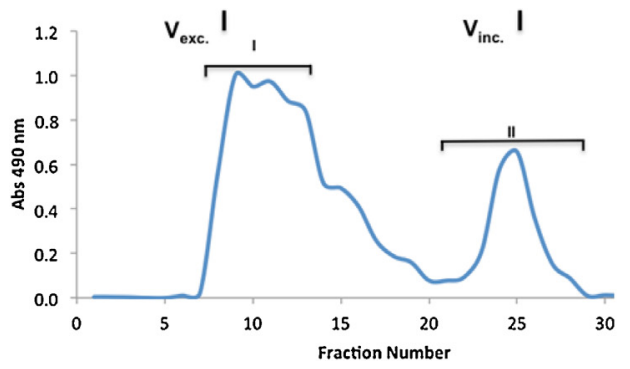

b)

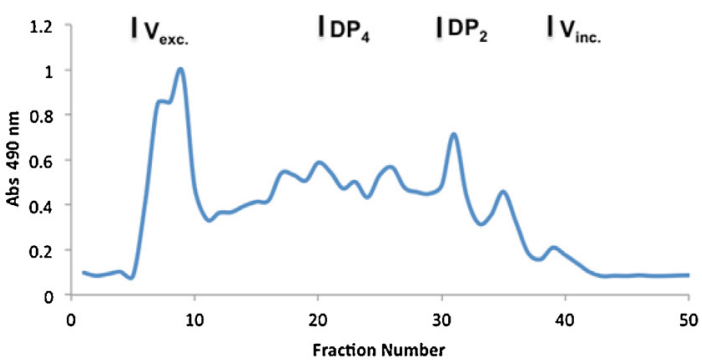

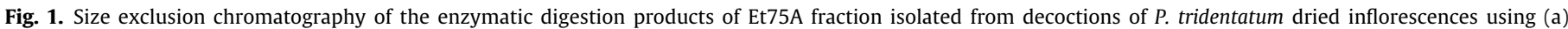
endo-polygalacturonase (a similar pattern was obtained for Et50A, data not shown) and (b) endo-( $\beta 1 \rightarrow 4)$-D-mannanase.

Table 2

Deduced linkages from neutral sugar methylation analysis of fractions isolated from decoctions of $P$. tridentatum dried inflorescences.

\begin{tabular}{|c|c|c|c|c|c|}
\hline \multirow[t]{2}{*}{ Linkage } & \multicolumn{5}{|l|}{ Fraction } \\
\hline & Et50A & Et50B & Et75A & Et75A-I & Et75B \\
\hline T-Rhap & - & 2.1 & - & - & 1.4 \\
\hline 1,2-Rhap & - & 2.9 & - & - & 1.3 \\
\hline 1,3-Rhap & - & - & - & - & 0.5 \\
\hline 1,2,4-Rhap & 0.5 & 2.8 & 0.2 & - & 1.7 \\
\hline 1,3,4-Rhap & - & - & - & - & 0.9 \\
\hline Total Rha & $0.5^{\mathrm{a}}(1.1)^{\mathrm{b}}$ & $7.8(7.1)$ & $0.0(0.0)$ & $0.0(0.2)$ & $5.8(5.9)$ \\
\hline T-Fucp & 1.5 & 1.7 & 0.2 & 1.0 & 1.1 \\
\hline Total Fuc & $1.5(0.8)$ & $1.7(0.0)$ & $0.2(0.0)$ & $1.0(1.2)$ & $1.1(0.6)$ \\
\hline T-Ara $f$ & 5.3 & 11.6 & 1.5 & 1.3 & 9.4 \\
\hline T-Arap & - & 2.9 & - & 0.8 & 1.9 \\
\hline 1,2-Araf & - & 0.9 & 0.3 & 0.3 & 0.7 \\
\hline 1,3-Araf & 0.7 & 1.2 & 0.5 & 0.5 & 1.6 \\
\hline 1,5-Araf & 8.5 & 11.7 & 1.6 & 1.5 & 15.9 \\
\hline 1,2,5-Araf & - & 4.0 & - & - & 2.0 \\
\hline 1,3,5-Araf & 0.7 & 1.5 & 0.2 & 0.2 & 1.6 \\
\hline Total Ara & $15.2(14.1)$ & $33.8(35.4)$ & $4.1(5.1)$ & $5.9(4.4)$ & $33.1(34.6)$ \\
\hline T-Xylp & 5.0 & 1.6 & 2.4 & 1.9 & 0.8 \\
\hline 1,2-Xylp & 2.4 & 0.5 & 1.0 & 0.5 & - \\
\hline $1,4-\mathrm{Xyl} p$ & 0.7 & 1.2 & 1.1 & 1.5 & 0.8 \\
\hline $1,2,4$-Xylp & 2.1 & 2.5 & 0.5 & 0.5 & 3.7 \\
\hline Total Xyl & $10.2(8.8)$ & $5.8(4.0)$ & $5.0(4.6)$ & $4.4(4.4)$ & $5.3(1.9)$ \\
\hline T-Manp & 0.8 & - & 1.5 & 1.4 & 0.4 \\
\hline 1,4-Manp & 12.0 & 0.5 & 27.7 & 32.2 & 2.4 \\
\hline 1,2,4-Manp & - & - & 1.9 & 1.8 & 0.3 \\
\hline 1,3,4-Man $p$ & - & - & 3.5 & & 0.3 \\
\hline 1,4,6-Manp & 4.3 & - & 9.5 & 10.6 & 0.5 \\
\hline Total Man & 17.1(19.1) & $0.5(1.0)$ & $44.1(44.5)$ & $46.0(48.0)$ & $3.9(4.4)$ \\
\hline T-Galp & 8.7 & 5.2 & 9.5 & 8.8 & 5.8 \\
\hline 1,2-Galp & 1.1 & - & 0.2 & 0.2 & - \\
\hline 1,3-Galp & 1.0 & 1.3 & 0.7 & 0.6 & 3.0 \\
\hline 1,4-Galp & 9.0 & 10.8 & 5.0 & - & - \\
\hline 1,6-Galp & 12.9 & 19.7 & 2.9 & 2.6 & 20.9 \\
\hline 1,3,6-Galp & 1.5 & 4.7 & 1.4 & 1.2 & 12.0 \\
\hline Total Gal & $34.2(32.4)$ & $41.7(44.4)$ & $19.7(20.1)$ & $13.4(16.7)$ & $41.7(45.5)$ \\
\hline T-Glcp & 1.5 & 2.3 & 1.3 & 1.2 & 2.5 \\
\hline 1,3-Glcp & - & - & 0.4 & - & 0.5 \\
\hline 1,4-Glcp & 8.6 & 6.2 & 18.1 & 22.9 & 4.0 \\
\hline 1,6-Glcp & - & - & 0.3 & 0.4 & 0.2 \\
\hline $1,2,4$-Glcp & - & - & 1.8 & 1.8 & 0.9 \\
\hline 1,3,4-Glcp & - & - & 0.6 & - & - \\
\hline 1,4,6-Glcp & 9.8 & - & 3.4 & 3.8 & 0.6 \\
\hline Total Glc & $19.9(23.7)$ & $8.5(8.1)$ & $25.9(25.7)$ & $30.1(26.2)$ & $8.7(7.2)$ \\
\hline
\end{tabular}

a molar\% obtained through linkage analysis.

b molar\% obtained through sugar analysis.

example, the ESI-MS/MS spectrum of acetylated oligosaccharide $\mathrm{Ac}_{2} \mathrm{Hex}_{3}(\mathrm{~m} / z$ 611), which presented product ions resultant from the loss of one acetylated hexose $(\mathrm{m} / z 407$ and 389, identified as $[\mathrm{AcHex} 2+\mathrm{Na}]^{+}$and $\left[\mathrm{AcHex}_{2 \mathrm{res}}+\mathrm{Na}\right]^{+}$, respectively), and combined loss of two acetylated hexose residues with formation of
$(\mathrm{Hex}+\mathrm{Na})^{+}$ion at $m / z 203$ that confirm the proposed structure. These identifications are corroborated by the product ions bearing acetylated hexoses, namely $\left[\mathrm{Ac}_{2} \mathrm{Hex}_{2}+\mathrm{Na}\right]^{+}$and $\left[\mathrm{Ac}_{2} \mathrm{Hex}_{2 \mathrm{res}}+\mathrm{Na}\right]^{+}$, at $m / z 449$ and 431, respectively), and the ions attributed to acetylated hexose leading to the $[\mathrm{AcHex}+\mathrm{Na}]^{+}$and $\left[\mathrm{AcHex}_{\mathrm{res}}+\mathrm{Na}\right]^{+}$, at 

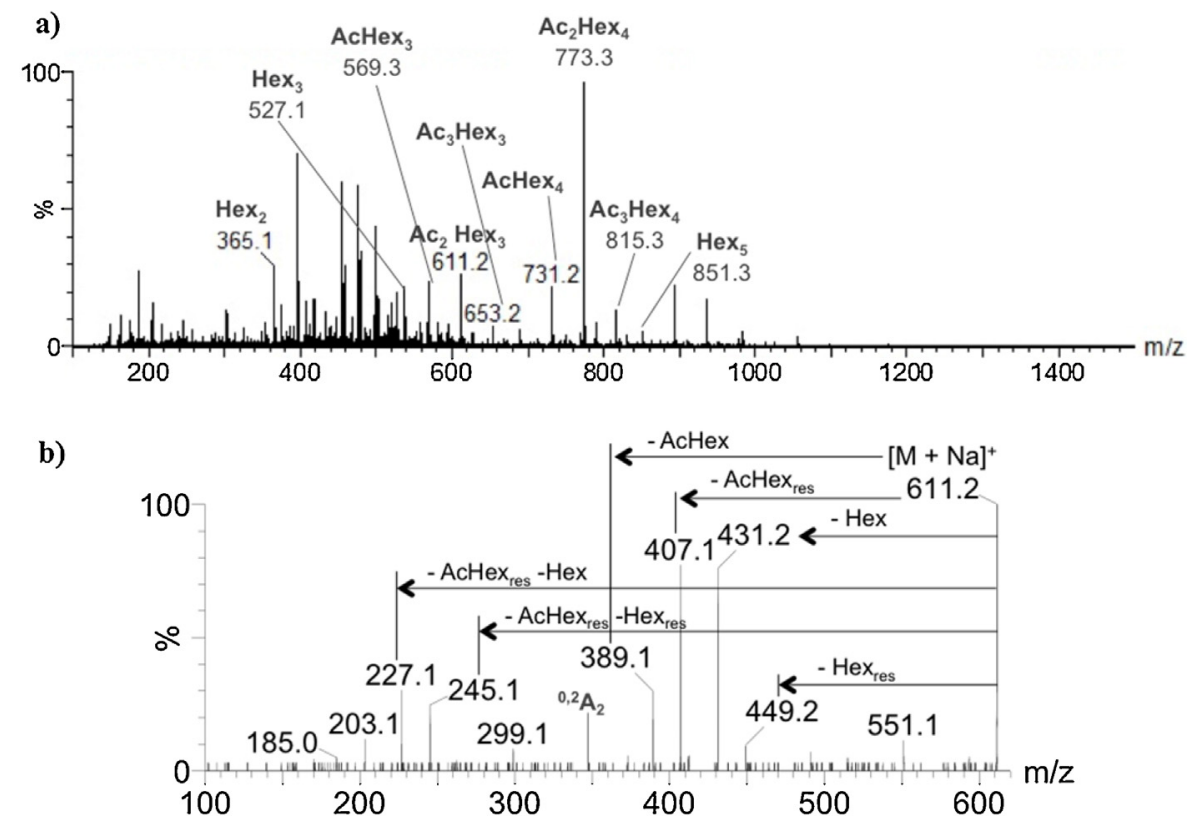

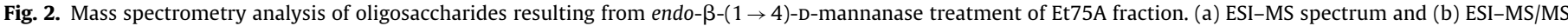
spectrum of the $[\mathrm{M}+\mathrm{Na}]^{+}$adducts of $\mathrm{Ac}_{2} \mathrm{Hex}_{3}(\mathrm{~m} / \mathrm{z} 611)$.
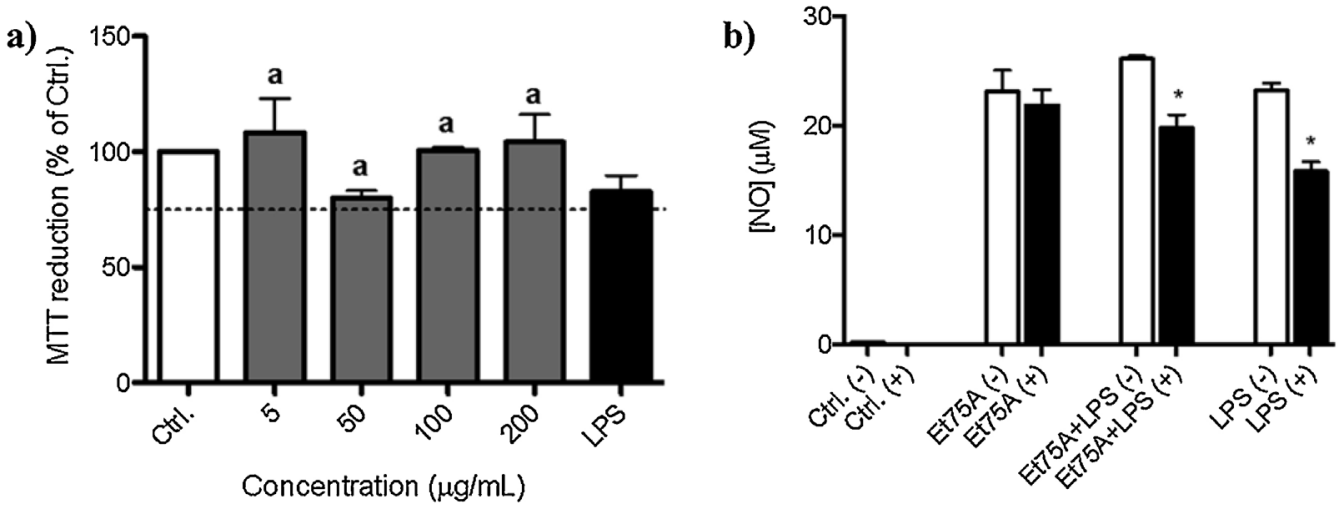

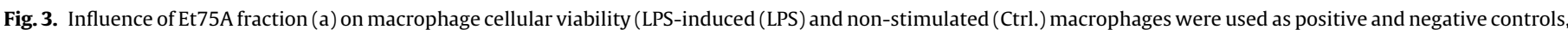

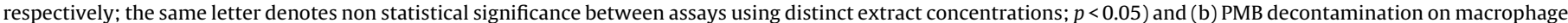
NO production. (- assays with no PMB decontamination; + assays with PMB decontamination; ${ }^{*}$ compared to assay without pre-incubation with PMB; $p<0.05$ ).

$m / z 245$ and 227, respectively. The product ion at $m / z$ 347, due to the combined loss of $162 \mathrm{Da}$ plus the loss of $102 \mathrm{Da}$, corresponding to an ${ }^{0,2} \mathrm{~A}_{2}$ cross-ring fragment, showed that the acetyl group was placed at $0-2$ position of the hexose residue (Nunes et al., 2005). As the loss of a hexose bearing two acetyl groups was not observed, each acetyl group are mainly linked to different hexose residues.

Overall, the analysis of MS spectra of mannanase digested Et75 fractions allowed to identify the series of PentAcHex $n$ resumed in Table 3. The presence of acetyl groups and pentoses linked to the mannan backbone has been reported for galactomannans from other origins, such as coffee beans (Nunes et al., 2005; Simões et al., 2010), locust bean gum (Simões et al., 2011), and Aloe vera (Simões et al., 2012). Also, revisiting the chromatograms of saponified fractions for quantification of pectic polysaccharides methylesterification, it was possible to identify the presence of acetic acid. Although not exclusive of galactomannans, the identification of acetic acid reinforces the hypothesis that these polysaccharides are acetylated.

\subsection{Macrophage cellular viability and NO production}

In order to disclose the potential contribution of polysaccharides of $P$. tridentatum decoctions to health benefits, Et75A fraction, which is representative of the different types of polysaccharides, as well as having the highest proportion of galactomannans, was used to study macrophage NO production. The effect of Et75A fraction on macrophage cellular viability was evaluated by the $3-(4,5-$ dimethylthiazol-2-yl)-2,5-diphenyl tetrazolium bromide (MTT) assay. For the range of concentrations comprised between 5 and $200 \mu \mathrm{g} / \mathrm{mL}$, Et75A did not compromised the macrophage cellular viability, which was similar, and always higher than $75 \%$, as observed for the control and LPS (Fig. 3a). This allowed to conclude that over the entire concentration range tested, Et75A fraction presented a safety profile to macrophages.

The immunostimulatory activity of Et75A fraction was evaluated by measuring the accumulation of nitrite, which is the stable end product of NO, in the RAW 264.7 macrophage cells supernatant. 

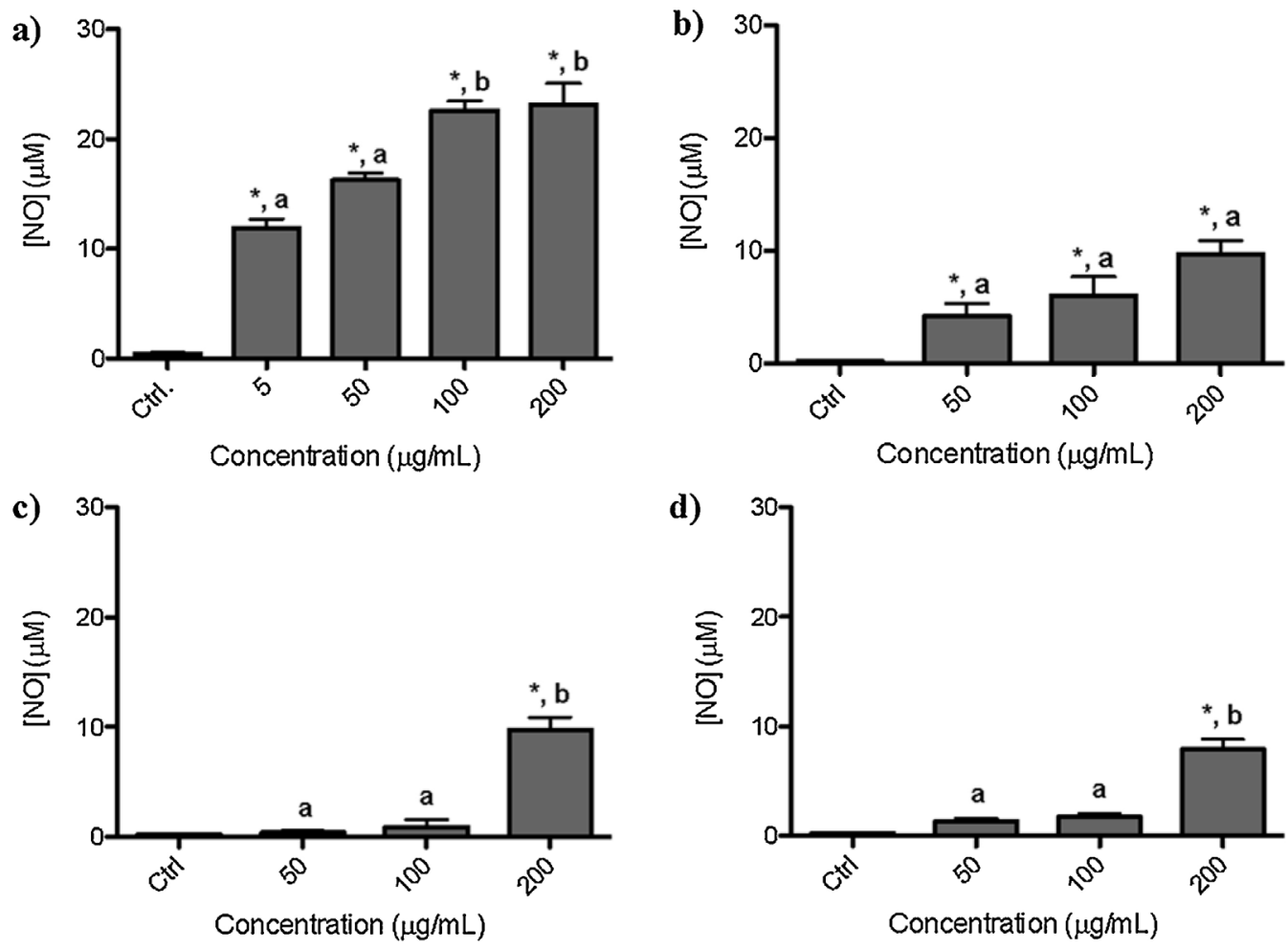

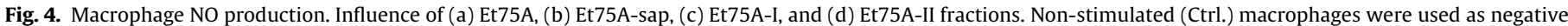
control. ( ${ }^{*}$ compared to Ctrl.; different letters denote significant differences between assays using distinct extract concentrations; $p<0.05$ ).

Table 3

Oligosaccharides identified in ESI-MS spectra of $\beta$-mannanase digestion products of Et75A fraction and further confirmed by ESI-MS/MS, with the identification of the $[\mathrm{M}+\mathrm{Na}]^{+}$ions $m / z$ value, and its composition.

\begin{tabular}{|c|c|c|c|c|c|}
\hline & \multirow[b]{2}{*}{$n$} & \multicolumn{4}{|c|}{ Number of acetyl groups } \\
\hline & & $\begin{array}{l}0 \\
m / z\end{array}$ & 1 & 2 & 3 \\
\hline $\operatorname{Hex}_{n}$ & $\begin{array}{l}2 \\
3 \\
4 \\
5 \\
6\end{array}$ & $\begin{array}{l}365 \\
527 \\
689 \\
851\end{array}$ & $\begin{array}{l}569 \\
731 \\
893 \\
1055\end{array}$ & $\begin{array}{l}611 \\
773 \\
935\end{array}$ & $\begin{array}{l}653 \\
815 \\
977\end{array}$ \\
\hline PentHex $_{n}$ & $\begin{array}{l}2 \\
3 \\
4 \\
5\end{array}$ & $\begin{array}{l}497 \\
821 \\
983\end{array}$ & $\begin{array}{l}539 \\
701 \\
863\end{array}$ & & \\
\hline
\end{tabular}

Table 4

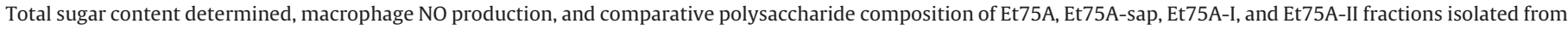
decoctions of $P$. tridentatum dried inflorescences.

\begin{tabular}{|c|c|c|c|c|c|c|c|c|}
\hline & Total Sugar(mass\%) & Macrophage NO production & HG & AG-I & AG-II & GM Ac & GM de-Ac & XG \\
\hline Et75A & 85.3 & +++ & +++ & + & + & ++ & - & ++ \\
\hline Et75A-sap & 85.3 & ++ & +++ & + & + & - & ++ & ++ \\
\hline Et75A-I & 86.7 & + & - & - & + & - & +++ & +++ \\
\hline Et75A-II & 97.4 & + & +++ & - & - & - & - & - \\
\hline
\end{tabular}

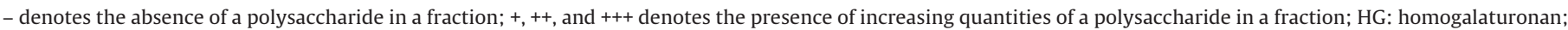
AG-I and AG-II: type-I and type-II arabinogalactans, respectively; GM: galactomannan; Ac and de-Ac: acetylated and de-acetylated, respectively; XG: xyloglucan.

When the macrophages were stimulated with concentrations of Et75A fraction ranging from 5 to $200 \mu \mathrm{g} / \mathrm{mL}$, an increase in the macrophage NO production, relatively to the control, was noticed (Fig. 4a), suggesting macrophage immunostimulatory activity. To confirm that the observed biological activity was caused by Et75A fraction and not by a possible endotoxin contamination, a polymyxin $\mathrm{B}$ (PMB) decontamination procedure was used. This pro- cedure was used because it is one of the most common, available and efficient for neutral polysaccharides LPS decontamination and because the $41 \mathrm{~mol} \%$ of UA residues in Et75A fraction were mainly methylesterified.

The pre-incubation with PMB did not decrease the NO production by macrophage stimulated with Et75A fraction (Fig. 3b). Additionally, as a decrease in NO production was observed when 
the macrophages were co-stimulated with LPS and Et75A, and with LPS, it was concluded that the observed immunostimulatory activity of the fraction present is not due to endotoxin contamination and is, indeed, an intrinsic bioactivity of the sample.

When the macrophages were stimulated with 50,100, and $200 \mu \mathrm{g} / \mathrm{mL}$ of Et75A-sap fraction, which resulted from a saponification treatment of $\mathrm{Et}_{75} \mathrm{~A}$ fraction, reductions of $60-75 \%$ in the NO production were observed relatively to Et75A fraction (Fig. 4b). Since the saponification treatment promotes de-acetylation and the acetylation has been reported as an important structural feature in the expression of galactomannans immunostimulatory activity (Karaca, Sharma, \& Nordgren, 1995; Simões et al., 2009, 2012), it can be concluded that the acetylated galactomannans of $P$. tridentatum present macrophage immunostimulatory activity. As Et75A-sap fraction still exhibited significant macrophage NO production, other polysaccharides besides the acetylated galactomannans may contribute to the immunostimulatory activity of Et75A fraction.

When the Et75A-sap fraction was further treated with endopolygalacturonase and the resulting products were fractionated in Bio-Gel P30, the high molecular weight fraction (Et75A-I) showed a decrease in the NO production of approximately $95 \%$ for 50 and $100 \mu \mathrm{g} / \mathrm{mL}$, and $60 \%$ for $200 \mu \mathrm{g} / \mathrm{mL}$, comparatively to Et75A (Fig. 4c). This decrease seems to result from the loss of AG-I side chains due to endo-polygalacturonase digestion and diffusion through the dialysis membrane. Et75A-I fraction only presented $2.2 \%$ of UA residues (Table 1 ) and $(1 \rightarrow 4)$-Galp residues, which are diagnostic for pectic polysaccharides AG-I side chains, were not detected (Table 2). As AG-I have been reported to contribute for macrophage NO production (Ferreira et al., 2015; Inngjerdingen et al., 2008), it is possible that $P$. tridentatum AG-I also contribute to Et75A immunostimulatory activity. Because de-acetylated galactomannans account for approximately $50 \%$ of the carbohydrates present in Et75A-I fraction, only when the macrophages were stimulated with $200 \mu \mathrm{g} / \mathrm{mL}$ a significant NO production was observed. Since Et75A-I fraction is also mainly composed by xyloglucans (Table 2), which are known to present immunostimulatory activity (Rosário et al., 2008, 2011), it is possible that P. tridentatum xyloglucans have also a contribution.

When the macrophages were stimulated with Et75A-II fraction, a significant activity was observed only for $200 \mu \mathrm{g} / \mathrm{mL}$ (Fig. 4d). This fraction contains low molecular weight galacturonans (96.5\% UA, Table 1), resulting from endo-polygalacturonase treatment of Et75A fraction and retained in $1 \mathrm{kDa}$ dialysis membrane. As the homogalacturonan moiety of pectic polysaccharides has been reported as macrophage immunostimulator (Belska et al., 2010; Wang et al., $2013,2014)$, it is possible that, when present in concentrations such as $200 \mu \mathrm{g} / \mathrm{mL}$, the homogalacturonan moieties of pectic polysaccharides from $P$. tridentatum dried inflorescences also contribute to macrophage NO production. Table 4 summarizes the relationship between the polysaccharide composition of the different fractions and their macrophage NO production.

\section{Conclusions}

The decoctions of $P$. tridentatum dried inflorescences contained pectic polysaccharides, type-I and type-II arabinogalactans, acetylated galactomannans, and xyloglucans, as shown by sugar and linkage analysis, mannanase and polygalacturonase treatments, and mass spectrometry analysis. Moreover, it was also possible to evidence some structural features of the galactomannans, namely the presence of acetyl groups at the $0-2$ of the mannose residues and the occurrence of pentose residues, possibly arabinose, similarly to what was observed for galactomannans from other sources.
The polysaccharides present in the decoctions of $P$. tridentatum dried inflorescences evidenced in vitro macrophage stimulatory activity, without compromising cellular viability. The major contribution to the observed immunostimulatory activity was due to the acetylation of the galactomannans. However, AG-I, homogalacturonans, and xyloglucans also contributed for the expression of macrophage immunostimulatory activity.

The present study highlights the role of polysaccharides on the bioactive properties frequently attributed by the popular tradition to the hot water extracts from $P$. tridentatum dried inflorescences.

\section{Acknowledgements}

Thanks are due to Fundação para a Ciência e a Tecnologia (FCT, Portugal), European Union, QREN, FEDER, and COMPETE for funding the QOPNA (Project PEst-C/QUI/UI0062/2013; FCOMP01-0124-FEDER-037296), CNC (Project UID/NEU/04539/2013), and CIMO Research Units, and RNEM (REDE/1504/REM/2005 that concerns the Portuguese Mass Spectrometry Network). Thanks are also due to FCT for the PhD Grant of Vitor Martins (SFRH/PROTEC/49249/2008) and to Dr. Ana Maria Carvalho, from CIMO, for the identification of the plant material.

\section{References}

Belska, N. V., Guriev, A. M., Danilets, M. G., Trophimova, E. S., Uchasova, E. G., Ligatcheva, A. A., et al. (2010). Water soluble polysaccharide obtained from Acorus calamus L. classically activates macrophages and stimulates Th1 response. International Immunopharmacollogy, 10, 933-942.

Blumenkrantz, N., \& Asboe-Hansen, G. (1973). New method for quantitative determination of uronic acids. Analytical Biochemistry, 54, 484-489.

Carpita, N. C., \& Gibeau, D. M. (1993). Structural models of primary cell walls in flowering plants: Consistency of molecular structure with the physical properties of the walls during growth. Plant Journal, 3, 1-30.

Carvalho, A. M. (2010). Plantas y sabiduría popular del Parque Natural de Montesinho. Un estudio etnobotánico en Portugal. Madrid: Editorial CSIC.

Cerqueira, M. A., Souza, B. W. S., Simões, J., Teixeira, J. A., Domingues, M. R. M., Coimbra, M. A., et al. (2011). Structural and thermal characterization of galactomannans from non-conventional sources. Carbohydrate Polymers, 83, 179-185.

Cheng, B.-H., Chan, J. Y.-W., Chan, B. C.-L., Lin, H.-Q., Han, X.-Q., Zhou, X., et al. (2014). Structural characterization and immunomodulatory effect of a polysaccharide HCP-2 from Houttuynia cordata. Carbohydrate Polymers, 103, 44-249

Coimbra, M. A., Delgadillo, I., Waldron, K. W., \& Selvendran, R. R. (1996). Isolation and analysis of cell wall polymers from olive pulp. In H. F. Linskens, \& J. F. Jackson (Eds.), Modern methods of plant analysis (pp. 19-44). Springer-Verlag.

Daas, P. J. H., Schols, H. A., \& de Jongh, H. H. J. (2000). On the galactosyl distribution of commercial galactomannans. Carbohydrate Research, 329, 609-619.

Dai, J., \& Mumper, R. J. (2010). Plant phenolics: Extraction, analysis and their antioxidant and anticancer properties. Molecules, 15, 7313-7352.

Ferreira, S. S., Passos, C. P., Madureira, P., Vilanova, M., \& Coimbra, M. A. (2015). Structure-function relationships of immunostimulatory polysaccharides: A review. Carbohydrate Polymers, 32, 378-396.

Franco, J. A. (1971). . Nova flora de Portugal (vol. 1) Lisboa: Sociedade Astória, Lda.

Fry, S. C. (1988). The growing plant cell wall: Chemical and metabolic analysis (1st ed.). Harlow: Longman Scientific \& Technical.

Gidley, M. J., \& Reid, J. S. G. (2006). Galactomannans and other cell wall storage polysaccharides in seeds. In A. M. Stephen, G. O. Phillips, \& P. A. Williams (Eds.), Food polysaccharides and their applications (pp. 181-216). Boca Raton: CRC Press.

Green, L. C., Wagner, D. A., Glogowski, J., Skipper, P. L., Wishnok, J. S., \& Tannenbaum, S. R. (1982). Analysis of nitrate, nitrite, and [15N] nitrate in biological fluids. Analytical Biochemistry, 126, 131-138.

Grosso, A. C., Costa, M. M., Ganço, L., Pereira, A. L., Teixeira, G., Lavado, J. M. G., et al. (2007). Essential oil composition of Pterospartum tridentatum grown in Portugal. Food Chemistry, 102, 1083-1088.

Hayashi, T., \& Kaida, R. (2011). Functions of xyloglucan in plant cells. Molecular Plant, 4, 17-24.

Hoffman, M., Jia, Z. H., Peña, M. J., Cash, M., Harper, A., Blackburn, A. R., II, et al. (2005). Structural analysis of xyloglucans in the primary cell walls of plants in the subclass Asteridae. Carbohydrate Research, 340, 1826-1840.

Inngjerdingen, M., Inngjerdingen, K. T., Patel, T. R., Allen, S., Chen Rolstad, B., et al. (2008). Pectic polysaccharides from Biophytum petersianum Klotzsch, and their activation of macrophages and dendritic cells. Glycobiology, 18, 1074-1084.

Inngjerdingen, K. T., Kiyohara, H., Matsumoto, T., Petersen, D., Michaelsen, T. E., Diallo, D., et al. (2007). An immunomodulating pectic polymer from Glinus oppositifolius. Phytochemistry, 68, 1046-1058. 
Inngjerdingen, K. T., Patel, T. R., Chen, X. Y., Kenne, L., Allen, S., Morris, G. A., et al. (2007). Immunological and structural properties of a pectic polymer from Glinus oppositifolius. Glycobiology, 17, 1299-1310.

Joseph, M. M., Aravind, S. R., George, S. K., Varghese, S., \& Sreelekha, T. T. (2013). A galactomannan polysaccharide from Punica granatum imparts in vitro and in vivo anticancer activity. Carbohydrate Polymers, 98, 1466-1475.

Karaca, K., Sharma, J. M., \& Nordgren, R. (1995). Nitric oxide production by chicken macrophages activated by acemannan, a complex carbohydrate extracted from Aloe vera. International Journal of Immunopharmacology, 17, 183-188.

Le Normand, M., Mélida, H., Holmbom, B., Michaelsen, T. E., Inngjerdingen, M., Bulone, V., et al. (2014). Hot-water extracts from the inner bark of Norway spruce with immunomodulating activities. Carbohydrate Polymers, 01, 699-704.

Mohnen, D. (2008). Pectin structure and biosynthesis. Current Opinion in Plant Biology, 11, 266-277.

Mosmann, T. (1983). Rapid colorimetric assay for cellular growth and survival: Application to proliferation and cytotoxicity assays. Journal of Immunological Methods, 65, 55-63.

Neves, J. M., Matos, C., Moutinho, C., Queiroz, G., \& Gomes, L. R. (2009). Ethnopharmacological notes about ancient uses of medicinal plants in Trás-os-Montes (Northern of Portugal). Journal of Ethnopharmacology, 124, 270-283.

Nunes, F. M., \& Coimbra, M. A. (2001). Chemical characterization of the high molecular weight material extracted with hot water from green and roasted arabica coffee. Journal of Agricultural and Food Chemistry, 49, 1773-1782.

Nunes, F. M., Domingues, M. R., \& Coimbra, M. A. (2005). Arabinosyl and glucosyl residues as structural features of acetylated galactomannans from green and roasted coffee infusions. Carbohydrate Research, 340, 1689-1698.

Nunes, C., Rocha, S. M., Saraiva, J., \& Coimbra, M. A. (2006). Simple and solvent-free methodology for simultaneous quantification of methanol and acetic acid content of plant polysaccharides based on headspace solid phase microextraction-gas chromatography (HS-SPME-GC-FID). Carbohydrate Polymers, 64, 306-311.

Nunes, F. M., Reis, A., Silva, A. M. S., Domingues, M. R. M., \& Coimbra, M. A. (2008) Rhamnoarabinosyl and rhamnoarabinoarabinosyl side chains as structural features of coffee arabinogalactans. Phytochemistry, 69, 1573-1585.

OíNeill, M., Albersheim, P., \& Darvill, A. (1990). The pectic polysaccharides of primary cell wall. In P. M. Dey, \& J. B. Harborne (Eds.), Methods in plant biochemistry (vol. 2) (pp. 415-442). Academic Press Limited.

Oliveira, A. S. B., \& Neiva, R. F. (2001). Plantas aromáticas e medicinais do Parque Natural da Serra da Estrela. Seia: CISE.

Paulsen, B. S., \& Barsett, H. (2005). Bioactive pectic polysaccharides. In T. Heinze (Ed.), Advances in polymer science (vol. 186) (pp. 69-101). Berlin, Heidelberg: Springer.

Paulsen, B. S. (2001). Plant polysaccharides with immunostimulatory activities. Current Organic Chemistry, 5, 939-950.

Peng, L., Xiang, F., Roberts, E., Kawagoe, Y., Greve, L. C., Kreuze, K., et al. (2001). The experimental herbicide CGA 325'615 inhibits synthesis of crystalline cellulose and causes accumulation of non-crystalline $\beta$-1, 4-glucan associated with CesA protein. Plant Physiology, 126, 981-992.

Ramberg, J. E., Nelson, E. D., \& Sinnott, R. A. (2010). Immunomodulatory dietary polysaccharides: A systematic review of the literature. Nutrition Journal, 9, $1-60$.

Ribeiro, J. A., Monteiro, A. M., \& Silva, M. L. F. (2000). Etnobotânica. Plantas bravias, comestíveis, condimentares e medicinais. Mirandela: João Azevedo Editor.
Rosário, M. M. T., Noleto, G. R., Bento, J. F., Reicher, F., Oliveira, M. B. M., \& Petkowicz, C. L. O. (2008). Effect of storage xyloglucans on peritoneal macrophages. Phytochemistry, 69, 464-472.

Rosário, M. M. T., Kangussu-Marcolino, M. M., do Amaral, A. E., Noleto, G. R., \& Petkowicz, C. L. O. (2011). Storage xyloglucans: Potent macrophages activators. Chemico-Biological Interactions, 189, 127-133.

Schepetkin, I. A., \& Quinn, M. T. (2006). Botanical polysaccharides: Macrophage immunomodulation and therapeutic potential. International Immunopharmacology, 6, 317-333.

Simões, J., Madureira, P., Nunes, F. M., Domingues, M. R., Vilanova, M., \& Coimbra, M. A. (2009). Immunostimulatory properties of coffee mannans. Molecular Nutrition and Food Research, 53, 1036-1043.

Simões, J., Nunes, F. M., Domingues, M. D. M., \& Coimbra, M. A. (2010). Structural features of partially acetylated coffee galactomannans presenting immunostimulatory activity. Carbohydrate Polymers, 79, 397-402.

Simões, J., Nunes, F. M., Domingues, M. R., \& Coimbra, M. A. (2011). Demonstration of the presence of acetylation and arabinose branching as structural features of locust bean gum galactomannans. Carbohydrate Polymers, 86, 1476-1483.

Simões, J., Nunes, F. M., Domingues, P., Coimbra, M. A., \& Domingues, M. R. (2012). Mass spectrometry characterization of an Aloe vera mannan presenting immunostimulatory activity. Carbohydrate Polymers, 90, 229-236.

Srivastava, M., \& Kapoor, V. P. (2005). Seed galactomannans: An overview. Chemistry and Biodiversity, 2, 295-317.

Teixeira, G., \& Pereira, A. L. (2004). Winged stems in Pterospartum tridentatum: Morphoanatomical study. Acta Botanica Gallica, 151, 103-109.

Tzianabos, A. O. (2000). Polysaccharide immunomodulators as therapeutic agents: Structural aspects and biologic function. Clinical Microbiology Reviews, 13, 523-533.

Vitor, R. F., Mota-Filipe, H., Teixeira, G., Borges, C., Rodrigues, A. I., Teixeira, A., et al. (2004). Flavonoids of an extract of Pterospartum tridentatum showing endothelial protection against oxidative injury. Journal of Ethnopharmacology, 93, 363-370.

Voragen, A. G. J., Coenen, G.-J., Verhoef, R. P., \& Schols, H. A. (2009). Pectin, a versatile polysaccharide present in cell walls. Structural Chemistry, 20, 263-275.

Waldron, K. W., \& Selvendran, R. R. (1990). Composition of the cell walls of different asparagus (Asparagus officinalis) tissues. Physiologia Plantarum, 80, 568-575.

Wang, H., Shi, S., Gu, X., Zhu, C., Wei, G., Wang, H., et al. (2013). Homogalacturonans from preinfused green tea: Structural characterization and anticomplementary activity of their sulfated derivatives. Journal of Agricultural and Food Chemistry, 61, 10971-10980.

Wang, H., Wei, G., Liu, F., Banerjee, G., Joshi, M., Annie Bligh, S. W., et al. (2014). Characterization of two homogalacturonan pectins with immunoodulatory activity from green tea. International Journal of Molecular Sciences, 15 9963-9978

Yang, X., Zhao, Y., Wang, H., \& Mei, Q. (2007). Macrophage activation by an acidic polysaccharide isolated from Angelica sinensis (Oliv.) Diels. Journal of Biochemistry and Molecular Biology, 40, 636-643.

Yang, L.-C., Lu, T.-J., Hsieh, C.-C., \& Lin, W.-C. (2014). Characterization and immunomodulatory activity of polysaccharides derived from Dendrobium tosaense. Carbohydrate Polymers, 111, 856-863.

Zou, Y.-F., Zhang, B.-Z., Inngjerdingen, K. T., Barsett, H., Diallo, D., Michaelsen, T. E., et al. (2014). Polysaccharides with immunomodulating properties from the bark of Parkia biglobosa. Carbohydrate Polymers, 01, 457-463. 